\title{
Simulation and optimisation in direct marketing Part 2: Developing optimisation models to boost results
}

Received (in revised form): 9th October, 2001

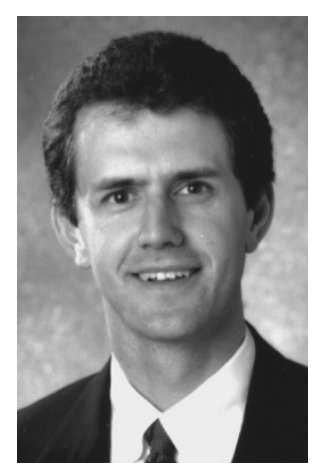

\section{P. Bruce McDoniel}

is the Vice-President of Database and Analysis at the Summit Marketing Group in St Louis, Missouri - an integrated marketing service company. Bruce has been in the database marketing industry for over ten years holding positions at GMAC and Mellon Bank. He is currently completing an Executive MBA at Washington University.

\section{J. Patrick Monteleone}

is currently the Senior Modelling Analyst at Summit Market Group. Pat has 12 years' experience in industry and academia and has held several positions in financial service marketing. Pat also holds a PhD in Management and Decision Sciences from Saint Louis University.

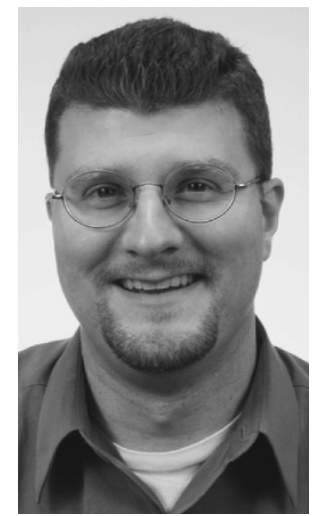

Dr J. Patrick Monteleone Summit Marketing Group, 132 East Monroe Avenue, St Louis, MO 63122-6125, USA.

Tel: +1 (314) 821 1135; Fax: +1 (314) 8217511 ; e-mail: Patrick.Monteleone@ summitmg.com

Abstract The first paper, 'Simulation and optimisation in direct marketing Part 1: Using simulation models to develop forecasts', in this two-part series proposed the development of a simulation model and the use of a discounted cash flow technique, return on promotion index (ROPI), to evaluate alternative mailing allocations. This study proposes the use of meta-heuristic optimisation techniques in conjunction with the business simulation model to determine the 'best' allocation decision considering the corporate marketing objective and its impact on financial performance.

\section{INTRODUCTION}

The mathematical approach to solving optimisation problems was first used during World War 2 when the British military recruited engineers and scientists to apply mathematical techniques to military deployment problems. ${ }^{1}$ The earliest civilian applications were in the production and finance departments of large manufacturing companies. In the 1950s and 1960s, optimisation models were used to solve multiperiod and multiregional production problems to smooth production demands. ${ }^{2}$ Optimisation was also frequently used to schedule crude oil production and manage cash flows in complex business environments. ${ }^{3}$

The uses of optimisation have expanded in recent years but remain dominant in the manufacturing and financial areas. Its use has been expanded to measure stock price movements, financial planning, lifecycle estimates among other risk evaluation scenarios. For example, Deloitte and Touche have developed an innovative approach to maximising shareholder value over a ten to 15 -year planning period. ${ }^{4}$ ProVise Management Group uses optimisation to weigh the risk/return trade-off of 
different portfolio options to maximise return given clients' risk tolerance levels. ${ }^{5}$ TRW has begun using the technique to estimate lifecycle costs and benefits associated with the airspace automation system for more accurate budget estimates. ${ }^{6}$

The use of optimisation in direct marketing research, however, has been relatively recent and is just starting to gain acceptance. The research has focused primarily on development of creative packages using conjoint analysis as the preferred method. For example, Vriens et al. proposed the use of conjoint analysis to improve direct mail effectiveness. $^{7}$ Other studies have focused on the selection of creative package elements and their optimal combinations. ${ }^{8,9}$

Even though the market is in its infancy, many are recognising the need to use resources better to produce desired results. Some authors have suggested optimisation techniques as a method of fine-tuning for the complete marketing effort. ${ }^{10}$ Porter-Kuchay describes how businesses have invested resources in solutions for automated data analysis, campaign execution, and customer communications and the consequent need to optimise resource allocation. ${ }^{11}$ Just as enterprise resource planning (ERP) software has gained a foothold in large business in the last decade, marketing as an investment has gained attention as a developing market for enterprise marketing solutions. ${ }^{12}$ As a result, the application of optimisation techniques in direct marketing has begun to show signs of greater acceptance. For example, Anthes describes the marriage of IBM operations research specialists with Fingerhut's direct marketing competencies, in a $\$ 3 \mathrm{~m}$ mailing optimisation project that reduced mailing costs by 6 per cent and increased profit by $\$ 3.5 \mathrm{~m}$ annually. ${ }^{13}$ This study continues examining optimisation in the direct marketing industry to illustrate its ability to improve key business metrics. This study also proposes the use of ROPI as a superior marketing objective on which to optimise assuming that profit maximisation is the corporate objective.

\section{METHODOLOGY}

A simulation model was built to quantify the new business acquisition process. The model was used to help forecast key performance metrics (for example total profit, sales, responses) given alternative mailing allocations. (For more information on the simulation model used in this study see McDoniel and Monteleone). ${ }^{14}$ The optimisation process was performed using four different objective variables and the impact evaluated across six key performance metrics in the simulation model. One month's mailings were optimised and a description of the six key performance metrics and the four objective variables are listed in Table 1.

Several meta-heuristic techniques were evaluated to determine the optimal solution for the simulation model. These techniques included scatter search, tabu search, genetic algorithms and simulated annealing. For further readings on meta-heuristic techniques see Michalewicz and Fogel. ${ }^{16}$

The method selected for this optimisation was the scatter search methodology developed by Glover, Kelly and Laguna. ${ }^{17}$ This technique is useful for general purpose optimisation problems and can easily accommodate maximisation and minimisation with requirements (goals, upper and lower bounds) and constraints. For further reading on the scatter search methodology see Glover and Laguna. ${ }^{18}$ 
Table 1: Performance metric and objective variable descriptions

\begin{tabular}{|c|c|c|c|}
\hline Item & $\begin{array}{l}\text { Performance } \\
\text { metric }\end{array}$ & $\begin{array}{l}\text { Optimisation } \\
\text { objective }\end{array}$ & Description \\
\hline $\begin{array}{l}\text { Return on promotion } \\
\text { index (ROPI) }\end{array}$ & $\mathrm{X}$ & $x$ & $\begin{array}{l}\text { Measure of profit. Calculated as the net present } \\
\text { value of contribution divided by the mailing } \\
\text { cost }^{15}\end{array}$ \\
\hline Contribution & $\mathrm{X}$ & & $\begin{array}{l}\text { Net present value of future net revenue stream } \\
\text { generated from campaign sales less variable } \\
\text { costs }\end{array}$ \\
\hline Total revenue & $\mathrm{X}$ & $\mathrm{X}$ & First year gross sales revenue \\
\hline Total responses & $\mathrm{X}$ & $\mathrm{X}$ & Total number of responses \\
\hline Total sales & $\mathrm{x}$ & & Total number of sales \\
\hline Cost per sale & $\mathrm{X}$ & $\mathrm{x}$ & Acquisition cost per sale \\
\hline
\end{tabular}

Table 2: Changes in key metrics

\begin{tabular}{lcccc}
\hline & $\begin{array}{l}\text { Maximise } \\
\text { ROPI } \\
\%\end{array}$ & $\begin{array}{l}\text { Minimise } \\
\text { cost/sale } \\
\%\end{array}$ & $\begin{array}{l}\text { Maximise } \\
\text { total } \\
\mathbf{\$} \text { sales } \\
\%\end{array}$ & $\begin{array}{l}\text { Maximise } \\
\text { total } \\
\text { responses } \\
\%\end{array}$ \\
Scenario & 42 & 29 & 18 & -52 \\
ROPI & 19 & 8 & 3 & -58 \\
Contribution & 23 & 23 & 27 & 0 \\
Total revenue & 23 & 22 & 75 & 97 \\
Number of responses & 23 & 34 & 21 & -13 \\
Number of sales & -13 & -20 & -2 & 52 \\
Cost per sale & \multicolumn{2}{c}{ Constant } \\
Mailing quantity & \multicolumn{2}{c}{} \\
\hline
\end{tabular}

\section{RESULTS}

The results of different optimisation scenarios were compared based on ROPI, contribution, total revenue, total number of responses, total number of sales, and cost per sale. Table 2 illustrates the change in key metrics compared to the initial allocation decision. Row 1 for example shows that ROPI increased by 42 per cent in the maximisation of ROPI scenario, increased 29 per cent in the minimisation of cost/sale scenario, increased by 18 per cent in the maximisation of total dollar sales scenario and decreased by 52 per cent in the maximisation of total response scenario.

For each combination of optimisation scenario and key performance metric, Table 3 lists the coefficients of variance. Coefficients of variance measure the degree of risk and are calculated as the standard deviation divided by the mean. Riskier scenarios have higher coefficients of variance than do less risky scenarios. In row 1, the initial allocation scenario had the lowest coefficient of variance (7 per cent) whereas the maximisation of total responses had the highest (44 per cent).

Table 4 illustrates changes in the marketing allocation across state and deciles. Boxes with a ' + ' indicate mail quantities increased and boxes with a '-' indicate that they decreased. A blank indicates that mailings were added to a state/decile combination in one of the other optimisation scenarios but not this specific optimisation scenario and that that states/decile combination was not included in the initial allocation. For example, in State 1/Decile 5, mail quantities were increased in each of the first three optimisation scenarios but were decreased or eliminated in the maximisation of total response scenario. 
Table 3: Coefficients of variance (risk factors)

\begin{tabular}{|c|c|c|c|c|c|}
\hline Scenario & $\begin{array}{l}\text { Initial } \\
\text { scenario } \\
\%\end{array}$ & $\begin{array}{l}\text { Maximise } \\
\text { ROPI } \\
\%\end{array}$ & $\begin{array}{l}\text { Minimise } \\
\text { cost/sale } \\
\%\end{array}$ & $\begin{array}{l}\text { Maximise } \\
\text { total } \\
\$ \text { sales } \\
\%\end{array}$ & $\begin{array}{l}\text { Maximise } \\
\text { total } \\
\text { responses } \\
\%\end{array}$ \\
\hline ROPI & 7 & 8 & 8 & 14 & 44 \\
\hline Contribution & 7 & 8 & 8 & 14 & 44 \\
\hline Total revenue & 5 & 6 & 6 & 9 & 14 \\
\hline Number of responses & 2 & 2.1 & 2.2 & 2.7 & 2.5 \\
\hline Number of sales & 5 & 5 & 5 & 8 & 11 \\
\hline Cost per sale & 5 & 5 & 5 & 7 & 11 \\
\hline Mailing quantity & & & Constant & & \\
\hline
\end{tabular}

Table 4: Changes in allocations

\begin{tabular}{lllll}
\hline $\begin{array}{l}\text { State and decile } \\
\text { allocations }\end{array}$ & $\begin{array}{l}\text { Maximise } \\
\text { ROPI }\end{array}$ & $\begin{array}{l}\text { Minimise } \\
\text { cost/sale }\end{array}$ & $\begin{array}{l}\text { Maximise } \\
\text { total sales }\end{array}$ & $\begin{array}{l}\text { Maximise } \\
\text { total responses }\end{array}$ \\
\hline State 1/Decile 1 & + & + & + & + \\
State 1/Decile 2 & + & + & + & - \\
State 1/Decile 3 & + & + & + & - \\
State 1/Decile 4 & + & + & + & - \\
State 1/Decile 5 & + & + & + & - \\
\hline State 2/Decile 1 & + & - & - & - \\
State 2/Decile 2 & - & - & - & - \\
State 2/Decile 3 & - & - & - & - \\
State 2/Decile 4 & - & + & - & - \\
State 2/Decile 5 & - & - & - & - \\
\hline State 3/Decile 1 & - & - & - & - \\
State 3/Decile 2 & - & - & - & + \\
State 3/Decile 3 & - & - & & + \\
State 3/Decile 4 & - & & & + \\
State 3/Decile 5 & - & & & + \\
\hline State 4/Decile 1 & + & & & + \\
\hline State 5/Decile 1 & & & & \\
\hline State 6/Decile 1 & & & & \\
State 6/Decile 2 & & & & \\
\hline State 7/Decile 1 & & & & - \\
\hline
\end{tabular}

\section{DISCUSSION}

Regardless of the marketing objective chosen, all four optimisation scenarios showed considerable change in the key performance indicators in comparison to the initial allocation decision. In the profit and sales scenarios, risk increased mildly. In the maximisation of total response, however, risk greatly increased. In every optimisation scenario, the initial allocation method was considerably altered to improve marketing results for the chosen marketing objective.

\section{Maximise ROPI}

This scenario saw the greatest percentage increase in profit $(42$ per cent vs 29 per cent, 18 per cent and -52 per cent) and contribution (19 
per cent $v$ s 8 per cent, 3 per cent and -58 per cent) compared to the other scenarios. Revenues, sales and responses also showed measured improvement resulting in lower cost per sale. Risk was relatively unchanged. Using ROPI as the objective variable shows substantial gains over the initial allocation decision.

\section{Minimise cost per sale}

While this scenario saw the greatest improvement in cost per sale $(-20$ per cent $v s-13$ per cent, -2 per cent and 52 per cent) as a result of generating 34 per cent more sales than the initial allocation scenario, it was not nearly as profitable as the first optimisation scenario. This scenario saw sales revenue increase at a 23 per cent rate (the same percentage as the maximise ROPI case), however these sales were not the higher margin sales and thus profits did not increase as much. Risk, like the maximisation of ROPI scenario, was relatively unchanged. Minimising cost per sale shows only mild ROPI gains over the initial allocation but falls short of its full profit potential.

\section{Maximise total dollar sales}

This scenario saw the greatest improvement in dollar sales (27 per cent vs 23 per cent, 23 per cent and 0 per cent), however the gains in dollar sales came at a penalty. Seventy-five per cent more responses had to be generated to produce only a 4 per cent increase in total dollar revenues over the initial scenario. This is reflected in an incremental decrease in cost per sale of only 2 per cent and a smaller increase in ROPI (18 per cent vs 42 per cent, 29 per cent and -52 per cent). Minimising total sales dollars shows only modest profit and cost per sale gains.

\section{Maximise total response}

Maximising total responses caused a significant increase in the number of responses (97 per cent) over the initial allocation. As a result, all financial performance metrics deteriorated significantly. ROPI fell by 52 per cent, contribution fell by 58 per cent and the cost per sale increased by 52 per cent. Risk increased by a factor of six. Extraordinary gains were realised in responses but at the expense of profitability and cost per sale.

\section{CONCLUSIONS}

In direct marketing companies, the direct marketing acquisition process is the primary determinant of sales, responses, revenues, costs and profits. Determining the mailing allocation across lists, offers, creatives, products, channels and predictive models that best meets the corporate objective can, however, be daunting. The mailing scenario in this study had thousands, if not millions, of allocation possibilities.

It is reasonable to assume that many companies have used combinations of subjective and analytical approaches to select an allocation method. This study suggests the use of meta-heuristic optimisation to choose the allocation quantities that best meet corporate marketing objectives. As was illustrated, every optimised model objective outperformed the initial allocation's objective by at least 20 per cent through changing the mailing allocation.

While optimisation can improve results, companies should be careful about choosing the metric(s) to optimise. These findings show that a strictly marketing metric such as total number of responses or total number of sales can produce adverse financial results. A preferred metric would be one that 
includes both financial and marketing results. As such, this study shows the benefits of a profitability metric such as ROPI or contribution. An alternative metric that is, however, both easier to calculate and usable in the short run is the minimisation of cost per sale objective. Maximisation of total responses or total sales should be avoided.

The gains realised through optimisation can strain an unprepared organisation as a result of more responses and sales being generated. Both the maximisation of sales and response scenarios produced large increases in the number of responses that an existing sales staff might not be able to handle. This could result in cost increases and make these scenarios even less attractive. Even the maximisation of profit and revenue scenarios should be carefully evaluated on their impact on organisational requirements.

In conclusion, this study has shown that optimisation can improve marketing results by bringing together other corporate initiatives (for example customer relationship management, lifetime value and response models) and increase the probability of achieving corporate marketing objectives.

\section{Limitations and areas for further consideration}

Perhaps a direct marketer has conflicting objectives and use of multiple objectives is an organisational goal that requires compromise. This study did not consider interaction between objective variables in a model. The objective variables were optimised individually without constraints on the remaining variables. Optimisation of a single variable may not be ideal for every direct marketer. One consideration for future research would be establishing additional constraints for other key performance metrics other than the objective variable alone.

\section{References}

1 Winston, W. L. (1991) 'Operations research: Applications and algorithms', PWS-Kent, Boston.

2 Murphy, F. H. (1998) 'Annotated bibliography on linear programming models', Interactive Transactions of ORMS, Vol. 1, No. 4, Oct-Dec.

3 Ibid.

4 Anonymous (1998) from www.decisioneering.com, 'Deloitte \& Touche helps maximise clients' shareholder value with crystal ball', downloaded September, 2001.

5 Anonymous (1999) from www.decisioneering.com, 'For ProVise management group, crystal ball is the key to optimizing portfolio profit', downloaded September, 2001.

6 Anonymous (1998) from www.decisioneering.com, 'Use of crystal ball pro provides TRW with increased flexibility and efficiency'.

7 Vriens, M., van der Scheer, H., Hoekstra, J. and Bult, J. R. (1998) 'Conjoint experiments for direct mail response optimisation', European Journal of Direct Marketing, Vol. 32, No. 3/4, pp. 323-339.

8 Akaah, I. P. and Korgaonkar, P. K. (1988) 'A conjoint investigation of the relative importance of risk relievers in direct marketing', Journal of Advertising Research, Vol. 28, August/September, pp. 38-44.

9 James, E. L. and Li, H. (1993) 'Why do consumers open direct mail?', Journal of Direct Marketing, Vol. 7, No. 2, pp. 34-40.

10 Moskowitz, H. (2000) 'Optimization fine-tunes marketing efforts', Credit Union Executive Journal, Vol. 40, Iss. 4, p. 25.

11 Porter-Kuchay, S. (2000) 'Multidimensional marketing', Target Marketing, Vol. 23, Iss. 1, pp. $50-52$.

12 Ibid.

13 Anthes, G. (2000) 'Optimal results', Computerworld, November.

14 McDoniel, P. B. and Monteleone, J. P. (2001) 'Simulation and optimisation in direct marketing Part 1: Using simulation models to develop forecasts', Journal of Database Marketing, Vol. 9, No. 1, September.

15 See McDoniel and Monteleone, above, for more information.

16 Michalewicz, Z. and Fogel, D. B. (1998) 'How to solve it: Modern heuristics', Springer, Berlin.

17 Glover, J. P., Kelly, P. and Laguna, M. (1996) 'New advances and applications of combining simulation and optimization', Proceedings of the 1996 Winter Simulation Conference, Charnes, J. M., Morrice, D. J.. Brunner, D. T. and Swain, J. J. (eds), pp. 144-152.

18 Glover, F. and Laguna, M. (1997) 'Tabu search', Kluwer Academic Publishers, Boston, pp. 408. 